\title{
A Three-dimensional Competition Evaluation Approach on Environmental Technology in China
}

\author{
Like Yuan \\ Institute of Foresight and Evaluation, Chinese Academy of Science and Technology for Development, 100038, Beijing, China
}

\begin{abstract}
Since 2000, a relatively complete system for environmental science and technology has been established. However, there are no clear quantitative results on the exact level of China's current environmental technology. This research has established a three-dimension technological evaluation model consisting of longitudinal technological gap judgment, horizontal technological level comparison and indepth technological development stage analysis. The results show that China's environmental technologies have formed the basic pattern of leading, parallel and tracking. Nearly half of China's technologies are in the pilot trial stage, while the technological leading countries are mainly concentrated in the industrialization stage. It's not easy to support the construction of national ecological civilization.
\end{abstract}

\section{Introduction}

China has just completed its third decade of sustained economic growth at a high rate. These economic achievements, however, have been realized at considerable environmental cost even though the government has been making great efforts in developing laws, regulations, institutions and human resources necessary to sustainable manage the environmental consequences of economic growth [1]. After China entered the New Normal Economy, during the "13th Five-year Plan", environmental protection ushers in rare historic opportunities and faces severe challenges. Scientific and technological development of environment shall not only offer technical support for conventional pollutant discharge reduction and environment quality improvement, but also face up to the competition from rapid development of green technologies in the world. It also bears on its shoulder the great burden of optimizing the economic growth pattern. Under new situations and circumstances, implementing the innovation-driven development strategy and optimizing allocation of scientific and technological resources have become outstanding issues in deepening the reform. In the environment field, it has become the priority facing various levels of governments to focus on the current situation and major demands of the scientific and technological development of environment in China, to carry out technical assessment, to have a better knowledge on China's technological development level, to select strategies for scientific and technological development of the environment on a reasonable and effective basis and to determine key points.

\section{Three-dimensional technology competition evaluation approach}

What are the "effects" achieved through a long period of technological catch-up and capacity accumulation? For developing countries, a major challenge is to catch up with developed countries. Nowadays, economic scholars tend to define catch-up as a narrowing of the gap in productivity and income between a leading country and a lagging country [2]. It has also been described as a process by which a late-developing country increases its technological capability vis-à-vis a leading country [3]. These studies suggest that catch-up may be measured using several indicators [4]. Our focus is on the technological aspects of catch-up, defined as substantial improvement of technological capabilities from technologically lagging countries in their process of closing the gap with incumbents in advanced countries, thereby approaching the global technological frontier. Rachel (1996) believed that differences in technological competence and opportunities caused by the technological gap were major factors that influenced transformation of pattern of technical progress from imitation to innovation [5]. Thus, late-development countries shall firstly focus on whether the technological gap among technology-leading countries is being widened or narrowed.

In reality, preference for late-development advantage normally makes late-development countries rely on the path of technology introduction. Technology introduction is an inevitable choice for developing countries in the initial stage of industry, but the development of industrial technology should not be regarded as an easy and quick enhancement process through technology introduction. It requires conscious

*Corresponding author: yuanlike@yeah.net 
technological efforts to finally achieve the independent innovation. Historically, the development of technological capabilities in lots of developing countries fell into a vicious circle of 'backward -introduction backward again - introduction again' [6]. In addition, as technology-leading countries face the catch-up of latedevelopment countries, they are continuously launching new technologies through R\&D so that their leading positions can be ensured. Meanwhile, by applying the restricted technology exporting strategy, catch-up of late-development countries with leading countries in technologies can be slowed down. Technological innovation has become a strategic support for improving social productive forces and the comprehensive national strength. Compared with technology-leading countries, especially benchmarking countries with the greatest comprehensive national strengths like the US, we would like to know the ranking of China. Thus, we also pay attention to the status of China's overall technical strength and its rank compared with technology-leading countries.

In the end, on the basis of reviewing the overall technical strength level, it is also necessary to further learn about the mastery of core fundamental technologies, technological development stage and other competition information. In international technological competitions, it is required to ensure and intensify the leading position of technology and be able to keep absolute competitive advantages at the source and key technological fields, so as to play a dominant role in the middle test and industrialization stages, and further acquire competitive edges in the middle and downstream industrial chain. On the basis of analyzing the trend of technological development and overall technological level, analysis on international technological competitions can help us to comprehensively understand development overview and prominent advantages of China's technologies in the international environment, analyze and compare significant gaps between China and other countries in scientific and technological development and China's development bottleneck, and discover and seek for major breakthroughs and opportunities for scientific and technological development in China.

With the continuous improvement of understandings of people on effects of technologies and continuous development of technological evaluation, paradigms and methods of technological evaluation have also shown some major development. Besides the conventional objective analysis method $[7,8,9]$, the basis of subjective analysis method is adopted for experts' subjective judgment [10], given the ease of capturing through this method all the softer aspects of technology related factors $[11,12]$. Due to the complexity and interaction in the modern society, especially for the judgment on the trend of future technological development that is full of uncertainties, there is no reasonable technological method to master the future. Therefore, the best way is to acquire information as much as possible, follow one's "intuition" in processing information, offer an insightful perspective and reach a basic consensus [13]. Relatively speaking, expert opinion survey has been most widely used. Based on the above considerations, the research is different from technological competition evaluations made by previous studies through papers, patents and other objective data; instead, it has established a 3dimensional technological evaluation model consisting of longitudinal technological gap judgment, horizontal technological level comparison and in-depth technological development stage analysis. By applying the method of questionnaire survey and taking the example of environmental field technologies, and based on judgment of experts, technological competitions in the field both at home and abroad have been investigated from different aspects.

\section{Methodologies}

In order to comprehensively evaluate the level of China's environmental technology development, we carried out a technology level survey to China's environmental technology according to the logic of "field-subfield-technology items". The key technologies involved in the survey mainly cover the following 9 subfields: Ecological rehabilitation, Water pollution control, Air pollution control, Soil pollution control, Environmental health and risk control, Marine environmental pollution control, Environmental protection industry, Worldwide environmental convention implementation and Recycling economy, a total of 125 technology items. As the research was mainly about the current status of China's technologies, the experts selected were all front-line $R \& D$ and management professionals. During the questionnaire process, after correcting some unclear questions and answers and deleting some invalid questionnaires by phone and e-mail, 210 experts who participated in the investigation effectively and 427 copies of valid questionnaires were finalized. The experts participating in the survey were mainly young professionals, most of whom possessed senior titles and half had studied or worked abroad. The whole structure of experts was reasonable with a good representativeness.

In the analysis of China's technology gap and the technological development stage, the paper used the maximum judgment method. For example, when judging "the change trend of the gap between China's technology level and the international leading level since 2006", there were N1, N2, N3 experts whose answers were "widening", "narrowing" and "to be confirmed" respectively. The corresponding options made by over $(\mathrm{N} 1+\mathrm{N} 2+\mathrm{N} 3) 2 / 3$ experts would be considered as the expert opinions of the project so as to obtain consistency. If the values were equal or the number of experts was too small, the project should be returned to the environmental technology research group for rejudgement to get a clear conclusion. After three rounds of expert meetings, a consensus was formed basically. But there were also few experts who had great differences about the judgement, making it difficult to make a clear judgment of the non-consensus technology. 


\section{Results}

\subsection{Longitudinal judgement on technology gap}

According to investigation results, compared with the international leading level, technological development of all sub-domains in the environment field in China is generally slowing down, especially in water pollution control, air pollution control, marine environment pollution, environmental protection industry, worldwide environmental convention implementation etc. Gaps between all key technologies and international leading levels are being narrowed down.

Table 1. the development trend of sub fields

\begin{tabular}{|c|c|c|c|c|}
\hline Sub-fields & $\begin{array}{c}\text { No } \\
\text { • }\end{array}$ & Narrowing & Widdening & $\begin{array}{l}\text { To be } \\
\text { certain }\end{array}$ \\
\hline $\begin{array}{c}\text { Ecological } \\
\text { rehabilitation }\end{array}$ & 17 & 16 & 0 & 1 \\
\hline $\begin{array}{c}\text { Water } \\
\text { pollution } \\
\text { control }\end{array}$ & 14 & 14 & 0 & 0 \\
\hline $\begin{array}{l}\text { Air pollution } \\
\text { control }\end{array}$ & 12 & 12 & 0 & 0 \\
\hline $\begin{array}{l}\text { Soil pollution } \\
\text { control }\end{array}$ & 12 & 11 & 1 & 0 \\
\hline $\begin{array}{c}\text { Environmenta } \\
1 \text { health and } \\
\text { risk control }\end{array}$ & 11 & 7 & 3 & 1 \\
\hline $\begin{array}{c}\text { Marine } \\
\text { environment } \\
\text { pollution } \\
\text { control }\end{array}$ & 4 & 4 & 0 & 0 \\
\hline $\begin{array}{c}\text { Environmenta } \\
1 \text { protection } \\
\text { industry }\end{array}$ & 14 & 14 & 0 & 0 \\
\hline $\begin{array}{c}\text { Worldwide } \\
\text { environmenta } \\
1 \text { convention } \\
\text { implementati } \\
\text { on }\end{array}$ & 3 & 3 & 0 & 0 \\
\hline $\begin{array}{l}\text { Recycling } \\
\text { economy }\end{array}$ & 38 & 37 & 1 & 0 \\
\hline Overall & $\begin{array}{c}12 \\
5\end{array}$ & 118 & 5 & 2 \\
\hline
\end{tabular}

\subsection{Horizontal Evaluation on Technology Level}

Among the 125 key technologies under investigation in the environment field, according to the judgment of experts, 26 key technologies have currently caught up with the international leading level. China synchronizes, has smaller gaps or is parallel with the international leading level in 45 key technologies. Over $40 \%$ technologies are still subject to the tracking stage, especially VOCs discharge reduction support and monitoring technology, system management techniques for watershed pollution control, organics pollution soil bio-remediation/bio-ventilation technology, pollutant ecotoxicological effect testing and prediction technology, key technologies for stereoscopic monitoring of coastal zone environment and other key technologies. Experts participating in the investigation generally believe that there are considerable gaps between some technologies and international leading levels; as for quite a few technologies, gaps are even more significant.

According to the distribution of basic patterns of technological competition in various sub-domains, among the key technologies under investigation, more than half technologies in sub-domains like ecological rehabilitation and worldwide environmental convention implementation have already caught up with international leading levels, while more than half of key technologies in sub-domains like water pollution control, soil pollution control, environmental health and risk control, marine environment pollution, and environmental protection industry are still subject to the state of tracking levels.

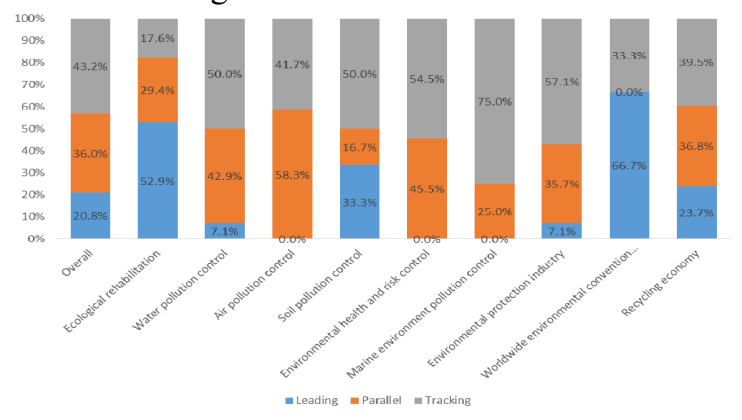

Figure 1. Technological development pattern of environmental field in China

\subsection{In-depth technological development stage analysis}

Through the survey of the 125 technology items in the environmental field, there are 18, 51 and 40 technologies in China which are in the laboratory stage, the pilotscale experimental stage and the industrialization stage. There are 16 technologies hard to be judged. From the quantitative point of view, most of China's technologies are in the laboratory and pilotscale experimental stage. Compared with the international leading level, there are 3,25 , and 87 international leading technologies in the laboratory stage, the pilotscale experimental stage and the industrialization stage. There are 10 technologies hard to be certained. It can be seen that among the key technologies in the survey, the technological leading countries are mainly concentrated in the industrialization stage. Excluding the uncertain technologies, the proportions of China's technologies in the laboratory stage, the pilotscale experimental stage and the industrialization stage are $16.5 \%, 46.8 \%$ and $36.7 \%$ (as shown in Figure 2), while those of the leading countries are $2.6 \% 21.7 \%$ and $75.7 \%$ respectively (as shown in Figure 3). The research on the technological competitions shows that China's environmental development stage has an obvious gap with the international leading level as a whole. 


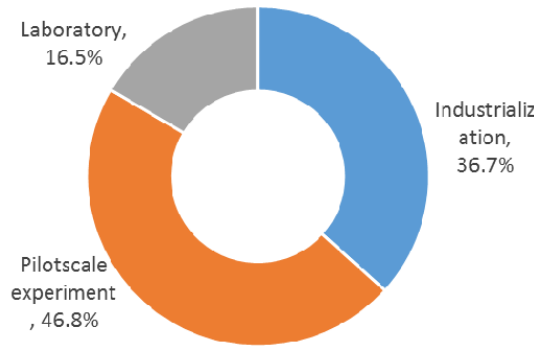

Figure 2. Distribution of technology development stages in China's environmental technology field

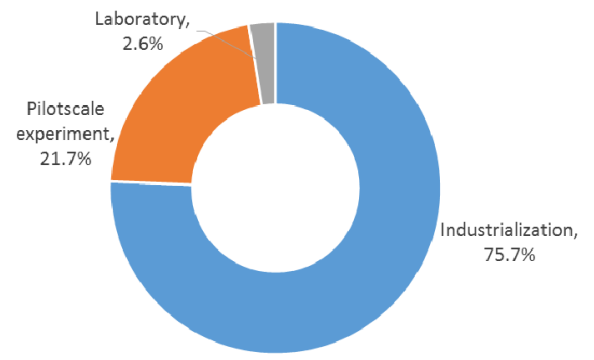

Figure 3. Distribution of technological development stages in leading countries

\section{Conclusions}

China's environmental problems occurred in a concentrated manner in the past 30 years, gradually worsened and attracted extensive concerns of general masses. Ever since 2000, China's environmental technologies have enjoyed rapid development. A relatively complete system for environmental science and technology has been established, which offers powerful scientific and technological support for environmental protection. By analyzing technological competitions based on three-dimensional technology evaluation model, China's overall research levels on environmental technologies have significant gaps with developed countries, while partial technologies take the leading place in the world. Research in the environment field is separated from applications, the industrialization level is low, and environmental protection industry fails to become a fundamental industry.

\section{References}

1. Zhang, Qingfeng, Crooks, Robert. 2012. Toward an Environmentally Sustainable Future: Country Environmental Analysis of the People's Republic of China. (C) Asian Development Bank. http://hdl.handle.net/11540/880. License: CC BY 3.0 IGO.

2. Fagerberg, J., Godinho, M. M. Innovation and catching-up. The Oxford handbook of innovation: 514-543. New York: Oxford University Press (2005)
3. Odagiri, H., Goto, A., Sunami, A., \& Nelson, R. R. (Eds.). Intellectual property rights, development, and catch up: An international comparative study. Oxford: Oxford University Press (2010).

4. Lee, K. Schumpeterian analysis of economic catchup: Knowledge, path-creation, and the middleincome trap. London: Cambridge University Press (2013)

5. Rachel van Elkan. Catching Up and Slowing Down: Learning and Growth Patterns in an Open Economy. Journal of International Economics, 3(41), 95111(1996)

6. Hong Yong, Su Jingqin, Lv Yibo,2010, Research on Catch-up oriental industrial technological capabilities growth in developing countries, Proceedings of the 7th international conference on innovation \& Management, December 4-5, 2010,WUHAN UNIVERSITY OF TECHNOLOGY, China

7. Van Zee, R.D., Spinler, S. Real option valuation of public sector R \& D investments with a down-andout barrier option. Technovation, 34 (8), 477484(2014)

8. Lee, S., Kim, W., Kim, Y.M., Lee, H.Y., Oh, K.J., The prioritization and verification of IT emerging technologies using an analytic hierarchy process and cluster analysis. Technological Forecasting and Social Change, 87, 292-304(2014)

9. Abbassi, M., Ashrafi, M., Tashnizi, E.S., Selecting balanced portfolios of R\&D projects with interdependencies: a cross-entropy based methodology. Technovation, 34 (1), 54-63(2014)

10. M. Choi , K. Chung, S. Lee and H.Seo, The evaluation of technology level on Korea's mid- and long-term strategic technologies, Journal of Korea Technology Innovation Society, (8), 651-677(2005)

11. Azzone, G., Manzini, R., Quick and dirty technology assessment: the case of an Italian Research Centre. Technoogical Forecasting and Social Change, 75 (8), 1324-1338(2008)

12. Facey, K., Boivin, A., Gracia, J., Hansen, H.P., Scalzo, A.L., Mossman, J., Single, A., Patients' perspectives in health technology assessment: a route to robust evidence and fair deliberation. International Journal of Technology Assessment in Health Care, 26 (03), 334-340(2010)

13. 14 John H. Vanston, Better forecasts, better plans, better results, Research Technology Management, 46(1): 47-58(2003) 